Profesor dr Milojko Jevtović, dipl. inž.

Elektrotehnički fakultet,

Banja Luka

Boban Pavlović,

kapetan, dipl. inž.

Vojna akademija,
Beograd

\section{ANALIZA TEHNIKA UPRAVLJANJA PRENOSOM PODATAKA}

\author{
UDC: $355.424 .3: 004.738$
}

Rezime:

U članku su predstavljene ARQ tehnike za upravljanje prenosom i kontrolu na nivou veze: , Stani i čekaj“, „,Vrati se unazad za $N^{\prime \prime} i$,,Selektivno odbacivanje“. Zatim je definisan važan parametar, kojim su analizirane osobine prenosa podataka na nivou veze i uprošćen prikaz karakteristika tehnika „Vrati se unazad za $N^{\text {“ }} i$ „,Selektivno odbacivanje“. Osnovni cilj rada odnosi se na definisanje kriterijuma za izbor odgovarajućeg protokola upravljanja na nivou veze koji će zadovoljiti zahteve korisnika (gubici, kašnjenje, varijacija kašnjenja, propusna moć). Na osnovu urađene simulacije, korišćenjem programa MATLAB 7.0, izvršeno je uporedenje vrednosti parametara karakterističnih za navedene tehnike i izvedeni zaključci o prednostima i manama pojedinih tehnika.

Ključne reči: prenos podataka, ARQ tehnike „Stani i čekaj“, „,Vrati se unazad za N“, „Selektivno odbacivanje".

\title{
ANALYSIS TESHNIQUES FOR FLOW DATA TRANSMISSION
}

Summary:

This article presents $A R Q$ techniques for flow and control at the link level: Stop-andWait, Go-back-N, and Selective-reject. Then it is defined an important parameter, necessary for analyzing characteristics of data transmission at the link level and simplified performances of the Go-back-N, and Selective-reject techniques. Main goal of this article refers to defining criteria for choosing proper protocol link control. By this criterion it is necessary to satisfy customer requirements like losses, delays, capacity, etc. By performing simulation (using MATLAB 7.0), comparison of the values of the techniques parameters is done and conclusions about advantages and disadvantages of certain techniques are given.

Key words: Data Transmission, ARQ techniques, Stop-and-Wait, Go-back-N, Selectivereject.

\section{Uvod}

Problem upravljanja prenosom podataka javlja se u nizu sistema koji zahtevaju komunikaciju u realnom vremenu, ili sa veoma ograničenim kašnjenjem, kao što su:

- sistemi za upravljanje vatrom zemaljske artiljerije;

- sistemi za upravljanje vatrom obalske artiljerije (SUVOA);
- sistemi za vazdušno osmatranje i javljanje (VOJ) pri prenosu podataka o ciljevima u vazdušnom prostoru;

- sistemi PVO pri prenosu podataka koji se odnose na navođenje raketnih sistema i letelica na ciljeve;

- sistemi za nadzor i kontrolu kretanja pešaka u štićenom prostoru ili u objektima; - multimedijalni informacioni sistemi, koji se koriste pri donošenju odluka u realnom vremenu, kao i u drugim sistemima. 
Cilj ovog rada je da se definišu kriterijumi za izbor protokola upravljanja vezom pri realizaciji konkretnih sistema za prenos podataka. Korisnik konkretnog sistema zahteva da se podaci prenose sa unapred ograničenim kašnjenjem, varijacijom kašnjenja i gubicima informacije pri prenosu od izvora do odredišta. Zadatak protokola za upravljanje prenosom jeste da se ti zahtevi ispune, odnosno zadovolje u datoj mreži za prenos podataka.

\section{Načini upravljanja prenosom $i$ greškama - osnovne karakteristike}

Jedan od veoma važnih zadataka u projektovanju telekomunikacionih mreža jeste da se obezbedi kvalitetan prenos podataka. Problem koji se pri tome javlja jeste - kako eliminisati greške koje se javljaju pri prenosu podataka ili multimedijalnog sadržaja.

Postoje dva osnovna načina za njihovo eliminisanje. Prvi je da se uz bitove doda dovoljno redundantnih bitova koji će omogućiti dekoderu da otkrije i koriguje greške nastale u prenosu. Detekcija i korekcija grešaka na mestu prijema obavlja se bez ponavljanja predaje, FEC (Forward-Error-Corection) [1]. Drugi je da se nakon detekcije grešaka na mestu prijema korekcija obavlja upućivanjem zahteva za ponavljanjem predaje i time osigura prenos podataka bez grešaka - detekcija grešaka na mestu prijema i automatsko ponavljanje zahteva za retransmisiju, postupak ARQ (Automatic-Repeat-reQuest).

Postupci ARQ široko se koriste $u$ računarskim mrežama pri prenosu podataka, zbog toga što su veoma jednostavni i omogućavaju postizanje velike tačnosti pri prenosu poruka. Nedostatak se ogleda u smanjenju efikasnosti, kada prijemnik dugo čeka na kodne reči bez grešaka, otpremajući zahteve za retransmisiju. Protokoli koji koriste postupak ARQ u korekciji grešaka su HDLC, SDLC, LAP, LAP-B, LAP-D, LAP-F, itd.

U FEC postupku korekcije grešaka nema povratnog kanala. Ukoliko je broj grešaka veći od broja grešaka koje dekoder može da detektuje i koriguje, poruka se prima sa greškama. Protokol ATM (Asynchronous Transfer Mode) koristi FEC postupak korekcije jednobitskih grešaka u zaglavlju ATM. On ne štiti informaciju, PDU (Payload Data Unit), već samo zaglavlje. Zbog toga je u kvalitetnim širokopojasnim mrežama prihvaćena ATM tehnika prenosa $\mathrm{i}$ komutacije.

Postoji mogućnost da se koriste tzv. hibridni postupci ARQ sa primenom retransmisije i procedurom FEC. Oni pružaju bolje performanse u poređenju sa pojedinačnim mogućnostima jednog od postupaka ARQ ili FEC.

U ovom radu akcenat je na ARQ postupcima upravljanja prenosom, pri čemu se zahteva pouzdan prenos podataka (tačnost informacije), a ne rad u realnom vremenu.

U postupku retransmisije poruka, razvijena su tri osnovna tipa ARQ postupka: „Stani i čekaj“ (Stop-and-Wait), „Vrati unazad za N karaktera“ (Go-backN) i „Selektivno odbacivanje“ (Selective-Reject). Poslednje dve tehnike su specijalni slučajevi tehnike „Pomičnog prozora“" (Sliding-Window) [2]. 


\section{Tehnika „Stani i čekaj“ (Stop-and-Wait)}

Najjednostavnija tehnika upravljanja greškama poznata pod nazivom ,Stani i čekaj" (slika 1) zasniva se na prenosu rama, pri čemu odredišna stanica šalje signal spremnosti za prijem sledećeg rama preko signala potvrde (ACKnowledgement), koji pokazuje da je kodna reč ispravno i uspešno primljena. Izvor mora sačekati prijem signala potvrde (ACK) pre nego što nastavi sa slanjem sledećeg rama. Negativna potvrda prijema, NAK (Negative AcKnowledgement) koju vrši prijemnik pokazuje da su u prenetoj kodnoj reči otkrivene (detektovane) greške. Predajnik ponavlja predaju kodne reči i ponovo čeka potvrdu prijema. Retransmisija se nastavlja sve dok prijemnik ne pošalje potvrdu o ispravnom prijemu (ACK).

Ovaj postupak, iako krajnje jednostavan, potencijalno je neefikasan zbog gubitka vremena pri čekanju potvrde prijema svake kodne reči. Rešenje bi bilo u povećanju dužine kodne reči, ali time raste verovatnoća greške, čime se povećava učestanost ponavljanja za svaku kodnu reč. S druge strane, blokovi velikih dužina nisu praktični zbog ograničenja koja nameću formati poruka.
Neka je $T_{\text {frame }}$ - vreme potrebno za prenos jednog rama, $T_{\text {prop }}$ - vreme potrebno za prenos poruke od izvora A do odredišta B na prenosnom linku i $T_{a c k}-$ vreme prenosa poruke potvrde. Ako se pretpostavi da je prenos bez grešaka, izvor A može da šalje ramove brzinom $\frac{1}{T_{\text {frame }}}$. Međutim, zbog potrebe za prijemom signala potvrde ACK, maksimalna brzina je smanjena na vrednost $\frac{1}{T_{\text {frame }}+2 \cdot T_{\text {prop }}+T_{\text {ack }}}$. Ukoliko je vreme prenosa na linku $T_{\text {prop }}$ veliko u odnosu na $T_{\text {frame }}$, doći će do znatnog smanjenja brzine prenosa u sistemu.

\section{ARQ tehnika ,Stani i čekaj“ bez grešaka u prenosu}

Najpre će biti posmatran slučaj kontrole protoka, pod pretpostavkom da ne dolazi do greške u prenosu. Na ovaj način može se definisati maksimalna bitska brzina prenosa ramova preko linka korišćenjem navedene tehnike pri prenosu bez grešaka. Pretpostaviće se da se poruka prenosi od stanice A do stanice B kao sekvenca uzastopnih ramova $F_{1}, F_{2}, \ldots, F_{n}$ na sledeći način:

- A šalje ram $F_{1}$,

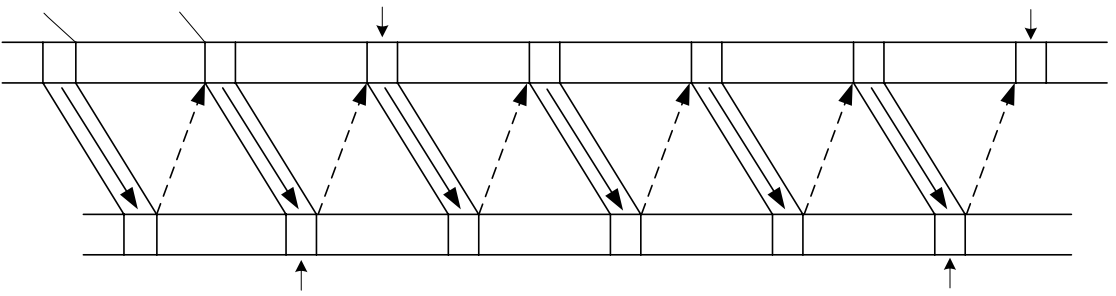

Sl. 1 - ARQ tehnika ,Stani i čekaj“ 
- B šalje signal potvrde (ACK),

- A šalje ram $F_{2}$,

- B šalje signal potvrde (ACK),

- A šalje ram $F_{n}$,

- B šalje signal potvrde (ACK).

Ukupno vreme potrebno za prenos podataka označiće se sa $n T$, gde je $n$ broj prenosa, a $T$ predstavlja zbir vremena slanja rama, prijema signala potvrde $\mathrm{i}$ spremnosti za predaju sledećeg rama. Imajući sve ovo u vidu, $T$ se može predstaviti na sledeći način:

$$
T=T_{\text {frame }}+T_{\text {prop }}+T_{\text {ack }}+T_{\text {prop }}+T_{\text {proc }}
$$

gde je:

$T_{\text {frame }}$ - vreme potrebno za prenos jednog rama (vreme za koje predajni deo u vezi pošalje sve bite unutar rama na prenosnu liniju),

$T_{\text {prop }}$ - vreme potrebno za prenos poruke (propagacije) od izvora A do odredišta B (ili u drugom smeru) na prenosnom linku, $T_{\text {proc }}$ - vreme obrade (procesiranja) u izvoru i odredištu kao odgovor na dolazni događaj (primljenu poruku),

$T_{a c k}$ - vreme prenosa poruke potvrde.

Ako se pretpostavi da je vreme obrade $T_{\text {proc }}$ zanemarljivo malo $\mathrm{i}$ da je vreme potvrde prenosa $T_{a c k}$ znatno kraće $\mathrm{u}$ poređenju sa vremenom prenosa podataka $\left(T_{p r o p}\right)$, uz fiksnu dužinu okvira (konstantno $T_{\text {frame }}$ ), tehnika upravljanja prenosom „Zaustavi i čekaj“ dopušta prenos podataka brzinom od jednog rama svakih $T$ sekundi, gde je $T$ dato izrazom:

$T=T_{\text {frame }}+2 T_{\text {prop }}$
Uzimajući u obzir prethodne pretpostavke, brzina prenosa se može predstaviti izrazom:

$\frac{1}{T}=\frac{1}{T_{\text {frame }}+2 T_{\text {prop }}}\left[\frac{\mathrm{ram}}{\mathrm{s}}\right]$

Radi lakše analize, poželjno je brzinu prenosa predstaviti preko normalizovane vrednosti. Ukoliko se ram prenosi u toku vremena $T_{\text {frame }}$ [s], tada je bitska brzina data izrazom $\frac{1}{T_{\text {frame }}}\left[\frac{\mathrm{ram}}{\mathrm{s}}\right]$. Na taj način, normalizovana brzina prenosa $\mathrm{S}$ može se predstaviti na sledeći način:

$S=\frac{\frac{1}{T_{\text {frame }}+2 T_{\text {prop }}}}{\frac{1}{T_{\text {frame }}}}=\frac{T_{\text {frame }}}{T_{\text {frame }}+2 T_{\text {prop }}}$

Ako se pretpostavi da je bitska brzina $R\left[\frac{b i t}{s}\right]$ i da je dužina rama $L[b i t]$, tada je brzina prenosa:

$L\left[\frac{\text { bit }}{\text { ram }}\right] \cdot \frac{1}{T}\left[\frac{\mathrm{ram}}{\mathrm{s}}\right]=\frac{L}{T_{\text {frame }}+2 T_{\text {prop }}}\left[\frac{\text { bit }}{\mathrm{s}}\right]$

Da bi se normalizovala vrednost brzine prenosa, podeliće se vrednost brzine prenosa $\mathrm{u}\left[\frac{b i t}{s}\right]$ sa bitskom brzinom, tako da se dobije:

$S=\frac{L /\left(T_{\text {frame }}+2 T_{\text {prop }}\right)}{R}$ 
Zamenom $T_{\text {frame }}=\frac{L}{R} \quad \mathrm{u}$ jednačini (4), dobija se jednačina (6).

Ovde se definiše parametar $a$ kao odnos vremena prenosa i trajanja rama:

$a=\frac{T_{\text {prop }}}{T_{\text {frame }}}$

Ako se jednačina (7) podeli sa $T_{\text {frame, }}$, dobiće se izraz za normalizovanu brzinu prenosa $S$ na sledeći način:

$$
S=\frac{1}{1+2 a}
$$

Ova vrednost predstavlja maksimalnu normalizovanu brzinu prenosa ostvarenu tehnikom prenosa „Stani i čekaj“, uz pretpostavku da nema grešaka u prenosu. Međutim, efektivna brzina prenosa je manja. Parametar $a$ je konstantne vrednosti ukoliko su vremena $T_{\text {prop }}$ i $T_{\text {frame }}$ konstantna, što je uobičajen slučaj: ramovi su fiksne dužine, izuzev poslednjeg u sekvenci poruke (predstavlja ostatak pri podeli paketa na blokove fiksne dužine), a i vreme kašnjenja je u prenosu na linku fiksne vrednosti $[3,4]$.

\section{ARQ tehnika ,Stani i čekaj “sa greškama u prenosu}

Ukupno vreme u toku koga se uspešno prenese ram između stanica A i B iznosi:

$$
T=T_{\text {frame }}+T_{\text {prop }}[s]
$$

Ako se pretpostavi da je došlo do gubitka rama ili da je poruka potvrde (ACK) izgubljena, ukupno vreme prenosa rama dato je relacijom:

$$
T=T_{\text {frame }}+T_{\text {out }}+T_{\text {frame }}+2 T_{\text {prop }}
$$

$T_{\text {out }}$ predstavlja vreme u toku kojeg nema prenosa (došlo je do greške). Pretpostaviće se da je ono jednako dvostrukom trajanju kašnjenja $u$ prenosu $\left(2 T_{\text {prop }}\right)$. Na ovaj način može se definisati pojam retransmisije: ukoliko radna stanica (izvor ili odredište) ne dobije poruku potvrde u vremenu dvostrukog trajanja kašnjenja u prenosu (propagacije) doći će do retransmisije (ponovnog slanja) rama.

Ako $N_{x}$ predstavlja srednji broj pokušaja da bi se ram uspešno preneo, tada je srednje vreme uspešnog prenosa rama dato izrazom:

$T=N_{x}\left(T_{\text {frame }}+2 T_{\text {prop }}\right)$

Primenom istog postupka, kao $\mathrm{u}$ prethodnom slučaju kada nema greške u prenosu, dolazi se do izraza za normalizovanu brzinu prenosa:

$$
S=\frac{T_{\text {frame }}}{N_{x}\left(T_{\text {frame }}+2 T_{\text {prop }}\right)}=\frac{1}{N_{x}(1+2 a)}(12)
$$

Srednji broj pokušaja $N_{x}$ može se izraziti preko verovatnoće greške u prenosu pojedinačnog rama $-P$. Ukoliko se pretpostavi da nikada neće doći do greške u prenosu signala potvrde (ACK), srednji broj pokušaja definisan preko matematičkog očekivanja dat je izrazom:

$$
\begin{aligned}
& N_{x}=E[\text { pokušaja }]=\sum_{i=1}^{\infty}\left(i \cdot P_{r}[(i) \text { pokušaja }]\right) \\
& N_{x}=\sum_{i=1}^{\infty}\left(i \cdot P^{i-1}(1-P)\right)=\frac{1}{1-P}
\end{aligned}
$$


Zamenom u izraz za normalizovanu brzinu prenosa, kod tehnike upravljanja prenosom i kontrole grešaka „Stani i čekaj“, dobija se:

$$
S=\frac{1-P}{1+2 a}
$$

\section{Parametar a}

Parametar a može se analizirati na više načina, u zavisnosti od definisanja pojedinih parametara [5]. Ako se pretpostavi da je:

$d$ - rastojanje na linku između dve radne stanice (izvor i odredište);

$V$ - brzina u prenosu signala na lin$\mathrm{ku}$. Za slobodan prostor kao medijum prenosa, brzina je jednaka brzini svetlosti $\left(c=3 \cdot 10^{8} \mathrm{~m} / \mathrm{s}\right)$. Za optičko vlakno brzina prenosa iznosi približno 0,67 brzine prostiranja svetlosti $\left(V \cong 2 \cdot 10^{8} \mathrm{~m} / \mathrm{s}\right)$;
$L$ - dužina rama [bit], konstantne vrednosti;

$$
R \text { - bitska brzina }\left[\frac{b i t}{s}\right] \text {; }
$$

vreme propagacije $\left(T_{\text {prop }}\right)$ odrediće se iz odnosa rastojanja $d$ i brzine prenosa $V$. Vreme prenosa rama na linku ( $\left.T_{\text {transm }}\right)$ predstavlja odnos dužine rama $L[$ bit $] \mathrm{i}$ bitske brzine $R\left[\frac{b i t}{s}\right]$. Zamenom u izraz za $a$, dobijamo da je:

$a=\frac{d / V}{L / R}=\frac{R \cdot d}{V \cdot L}$

Na slici 2, $T_{\text {transm }}$ je normalizovano na vrednost 1 , tako da je vreme propagacije $T_{\text {prop }}=a$. U slučaju kada je $a>1$, dužina linka je veća od dužine rama, što je prikazano na slici 2 (a), pri čemu se ne uzima u obzir vreme prenosa poruke ACK. Stanica A u ko-

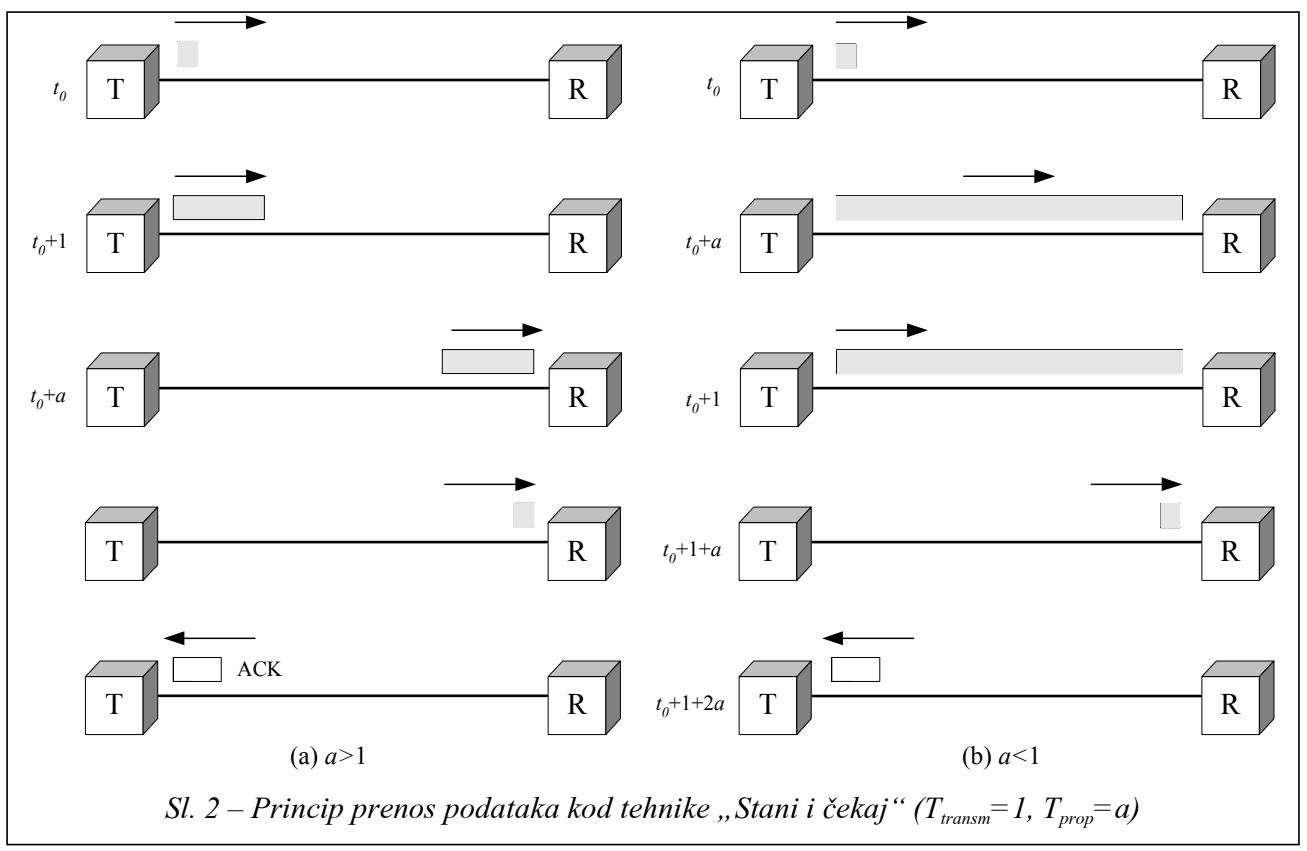


munikaciji A-B počinje sa predajom rama $\mathrm{u} t=0$. $\mathrm{U} t=1$, A završava sa predajom rama. $\mathrm{U}$ trenutku $t=a$ (vreme propagacije), prednja ivica rama dolazi na prijemnu stanicu $B$. $\mathrm{U} t=1+a, \mathrm{~B}$ je primila celokupan ram i neposredno zatim šalje poruku potvrde ACK. Ova poruka stiže do A u $t=1+2 a$. Ukupno utrošeno vreme za prenos iznosi $t=1+2 a$. Samim tim, određena je i brzina kojom se ramovi mogu prenositi, $\frac{1}{1+2 a}$. Isti rezultat biće postignut i u slučaju kada je $a<1$ (dužina rama je veća od rastojanja na linku).

Biće razmotreno nekoliko slučajeva primene ARQ postupka „Stani i čekaj“ (slika 3) i analiziran ARQ postupak na primeru jedne WAN (Wide Area Network) mreže sa ATM u kojoj se nalaze dve stanice međusobno udaljene hiljadama kilometara. Standardni ATM ram naziva se ćelija i sadrži 53 bajta, odnosno 423 bita $(53 \times 8)$, pri čemu je jedna od standardnih bitskih brzina $155,52 \mathrm{Mb} / \mathrm{s}$. $\mathrm{Na}$ ovaj način definisano, ukupno vreme prenosa rama (ATM ćelije) iznosi

$$
\frac{424[\text { bit }]}{155,2 \cdot 10^{6}\left[\frac{\text { bit }}{\mathrm{s}}\right]}=2,7 \cdot 10^{-6}[\mathrm{~s}] \text {. }
$$

Ako se pretpostavi da je prenosni medijum optički link, na udaljenosti od 2000 $\mathrm{km}\left(\mathrm{d}=2 \cdot 10^{6} \mathrm{~km}\right)$, vreme propagacije iznosi $T_{\text {prop }}=\frac{2 \cdot 10^{6} \mathrm{~m} \cdot \mathrm{s}}{2 \cdot 10^{8} \mathrm{~m}}=1 \cdot 10^{-2}[\mathrm{~s}]=10[\mathrm{~ms}]$. Konačno, dobija se da je vrednost parametra $a=\frac{1 \cdot 10^{-2}}{2,7 \cdot 10^{-6}} \cong 3703$, pri čemu normalizovana brzina prenosa iznosi svega $S=\frac{1}{1+2 a} \approx \frac{1}{7407} \cong 0,000135$.

Drugi slučaj predstavlja primer mreže LAN (Local Area Network). U ovom primeru rastojanja su u opsegu od 0,1 do $10 \mathrm{~km}$, sa bitskim protocima od $10 \mathrm{Mb} / \mathrm{s}$ do $1 \mathrm{~Gb} / \mathrm{s}$, pri čemu veće brzine prenosa odgovaraju kraćim rastojanjima. Ako je $V=2 \cdot 10^{8}[\mathrm{~m} / \mathrm{s}]$, dužina rama $L=1000$ [bit] i bitska brzina $R=10[\mathrm{Mb} / \mathrm{s}]$, za zadati opseg rastojanja $d$ dobija se vrednost parametra $a$ između 0,005 i 0,5. Time se dobija vrednost za normalizovanu brzinu prenosa $S$ između 0,5 i 0,911 . Za 100 $\mathrm{Mb} / \mathrm{s}$ LAN-ove, uz odgovarajuća kraća rastojanja, dobiće se takođe približno iste vrednosti brzine prenosa. Može se zaključiti da su LAN mreže prilično

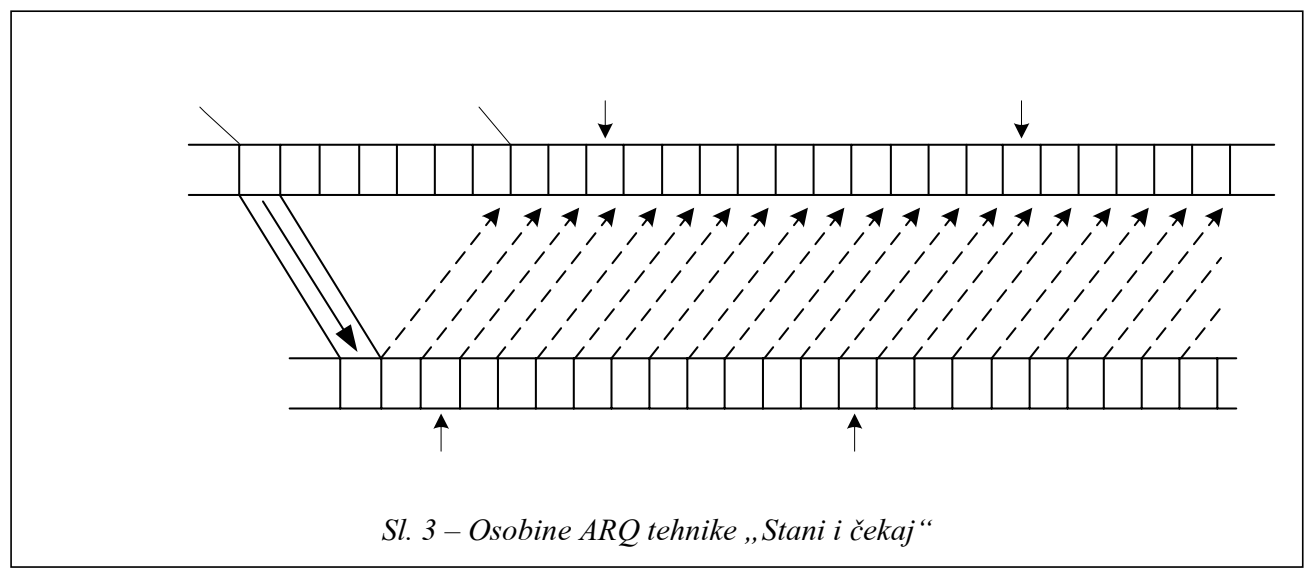


efikasne po brzini prenosa uz primenu ARQ tehnike, dok u slučaju WAN mreža (ATM) ova tehnika ne daje rezultate, zbog čega se primenjuje FEC tehnika detekcije i korekcije u prenosu podataka.

$\mathrm{Na}$ kraju, biće posmatran slučaj digitalnog prenosa preko modemske linije brzinom od $R=28,8 \mathrm{~kb} / \mathrm{s}$. Ponovo će se pretpostaviti da je dužina rama $L=1000$ [bit]. Dužina prenosnog linka iznosi između nekoliko desetina metara do nekoliko hiljada kilometara. Ukoliko je rastojanje od $d=1500 \mathrm{~m}$, tada je $a=\frac{d / V}{L / R}=\frac{d \cdot R}{L \cdot V}=\frac{1500 \mathrm{~m} \cdot 28800 \frac{\mathrm{bit}}{\mathrm{s}}}{1000 \mathrm{bit} \cdot 2 \cdot 10^{8} \frac{\mathrm{m}}{\mathrm{s}}}=$ $=2,16 \cdot 10^{-4}$, pri čemu normalizovana brzina prenosa iznosi $S=\frac{1}{1+2 a} \approx 1$, tačnije 0,99978 .

Čak i u slučaju velikog rastojanja, npr. $d=6000 \mathrm{~km}$, uz zadržavanje vrednosti ostalih parametara, dolazi se do vrednosti $a=\frac{6 \cdot 10^{6} \cdot 28800}{1000 \cdot 2 \cdot 10^{8}}=0,864$, tako da je $S=\frac{1}{1+2 a} \cong 0,4$, tačnije 0,366 .

Da bi se uočio efekat parametra $a$ na normalizovanu brzinu prenosa (propusnu moć), predstaviće se zavisnost $S=\frac{1-P}{1+2 a}$ od promene parametra $a \mathrm{za}$ zadatu verovatnoću $P$ (verovatnoća da je preneti ram sa greškom). Posmatraće se familija krivih za vrednosti verovatnoće greške u prenosu $P=10^{-3} ; 10^{-2} ; 10^{-1} ; 0,2$; 0,$3 ; 0,4$ i 0,5 . Može se zaključiti da se sa porastom verovatnoće greške u prenosu $P$, smanjuje vrednost normalizovane br- zine $S$, ali je ta zavisnost mala u velikom opsegu vrednosti $P$ (za $P=10^{-3}$ i $10^{-2}$ dobija se praktično ista kriva). Takođe, za vrednosti parametra $a$ veće od 100, zavisnost verovatnoće $P$ na vrednost $S$ je zanemarljiva.

Neke karakteristične vrednosti parametra a

\begin{tabular}{|c|c|c|c|}
\hline $\begin{array}{l}\text { Bitska } \\
\text { brzina } \\
(\mathrm{Mb} / \mathrm{s})\end{array}$ & $\begin{array}{c}\text { Dužina rama } \\
\text { (bit) }\end{array}$ & $\begin{array}{c}\text { Rastojanje } \\
(\mathrm{km})\end{array}$ & Parametar $a$ \\
\hline 0,064 & 1000 & 0,1 & 0,00003 \\
\hline 0,064 & 1000 & 1 & 0,0003 \\
\hline 0,064 & 1000 & 35,863 & 7,65 \\
\hline 0,064 & 10000 & 0,1 & 0,000003 \\
\hline 0,064 & 10000 & 1 & 0,00003 \\
\hline 0,064 & 10000 & 35,863 & 0,77 \\
\hline 1 & 1000 & 1 & 0,005 \\
\hline 1 & 1000 & 3000 & 15 \\
\hline 1 & 1000 & 35,863 & 119,5 \\
\hline 1 & 10000 & 1 & 0,0005 \\
\hline 1 & 10000 & 3000 & 1,5 \\
\hline 1 & 10000 & 35,863 & 11,95 \\
\hline 10 & 1000 & 0,05 & 0,0025 \\
\hline 10 & 1000 & 0,5 & 0,025 \\
\hline 10 & 10000 & 0,05 & 0,00025 \\
\hline 10 & 10000 & 0,5 & 0,0025 \\
\hline 100 & 1000 & 0,1 & 0,05 \\
\hline 100 & 10000 & 0,1 & 0,005 \\
\hline 1000 & 1000 & 0,1 & 0,5 \\
\hline 1000 & 10000 & 0,1 & 0,05 \\
\hline
\end{tabular}

Tehnika „Pomičnog prozora“ (Sliding-Window)

Osnovni problem prethodne tehnike jeste što se u toku određenog vremena može prenositi samo jedan ram [6]. Situa- 


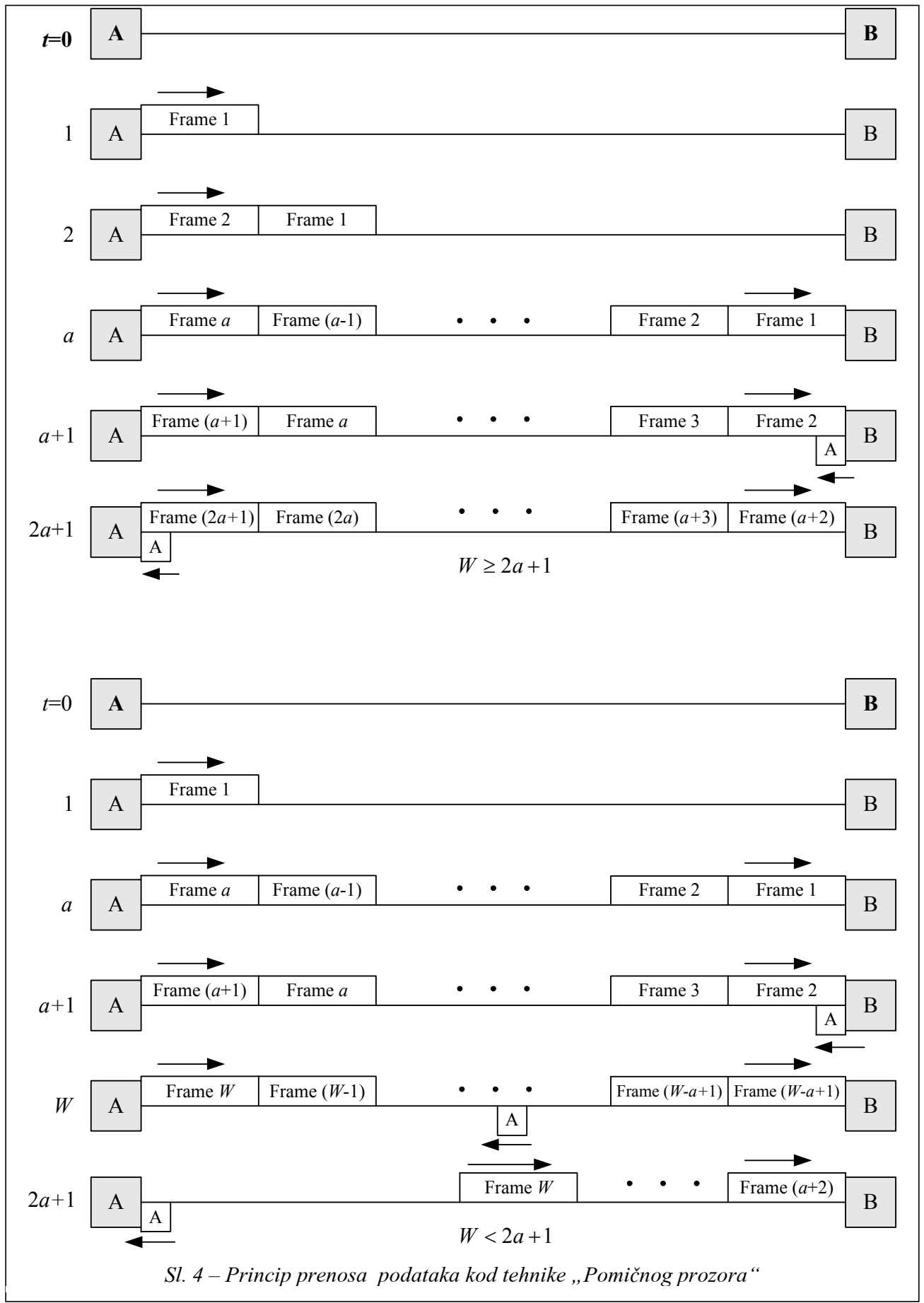


cija kada je vreme prenosa (predstavljeno sa $\left.T_{\text {prop }}\right)$ veće od trajanja rama $\left(T_{\text {frame }}\right)$ dolazi do velike neefikasnosti prenosa.

Ako se pretpostavi da su dve radne stanice A i B povezane dupleksno i da se na mestu B nalazi bafer za $n$-ramova, stanica B može prihvatiti $n$-ramova, tako da stanica A može poslati $n$-ramova bez čekanja na pristizanje signala potvrde (ACK).

Biće razmotrene dve tehnike pomičnog prozora: ARQ tehnika „Vrati se unazad za N“ i ARQ tehnika „Selektivnog ponavljanja“. Osnovna razlika između ovih tehnika je u načinu obrade grešaka u prenosu.

\section{Algoritam tehnike „Pomičnog prozora" bez grešaka}

U slučaju pomičnog prozora, brzina prenosa na liniji zavisi od dva faktora veličine prozora $W$ i vrednosti parametra $a$. Radi pojednostavljenja, smatraće se da normalizovana vrednost vremena prenosa rama $T_{\text {frame }}$ iznosi 1; tada je vreme pro- pagacije $T_{\text {prop }}$ jednako $a$. Slika 4 predstavlja primer potpune dupleksne veze. Stanica A (izvor) počinje da emituje sekvencu ramova u trenutku $t=0$. Prednja ivica prvog rama odlazi na stanicu B (odredište) $\mathrm{u} t=a$. Prvi ram je u potpunosti primljen u $t=a+1$. Pretpostavljajući da je vreme obrade minornog trajanja, B će trenutno primiti informaciju o potvrdi za prvi pristigli ram (ACK1). Pretpostaviće se da je dužina poruke potvrde mala, tako da je vreme njenog prenosa $T_{a c k}$ veoma kratko. Samim tim, signal ACK1 stiže u A u trenutku $t=2 a+1$.

Da bi se analizirale osobine navedene tehnike, razmotriće se dva slučaja:

- $W \geq 2 a+1$ - potvrda za prvi ram stiže u stanicu A pre nego što A završi sa kompletnim slanjem svog prozora širine $W$. Na taj način, A može slati poruke u kontinuitetu, bez prekida, tako da je normalizovana propusna moć $S=1$;

- $W<2 a+1$ - stanica A završava slanje svog prozora u $t=W$ i ne može slati dodatne ramove posle $t=2 a+1$. Ovako de-

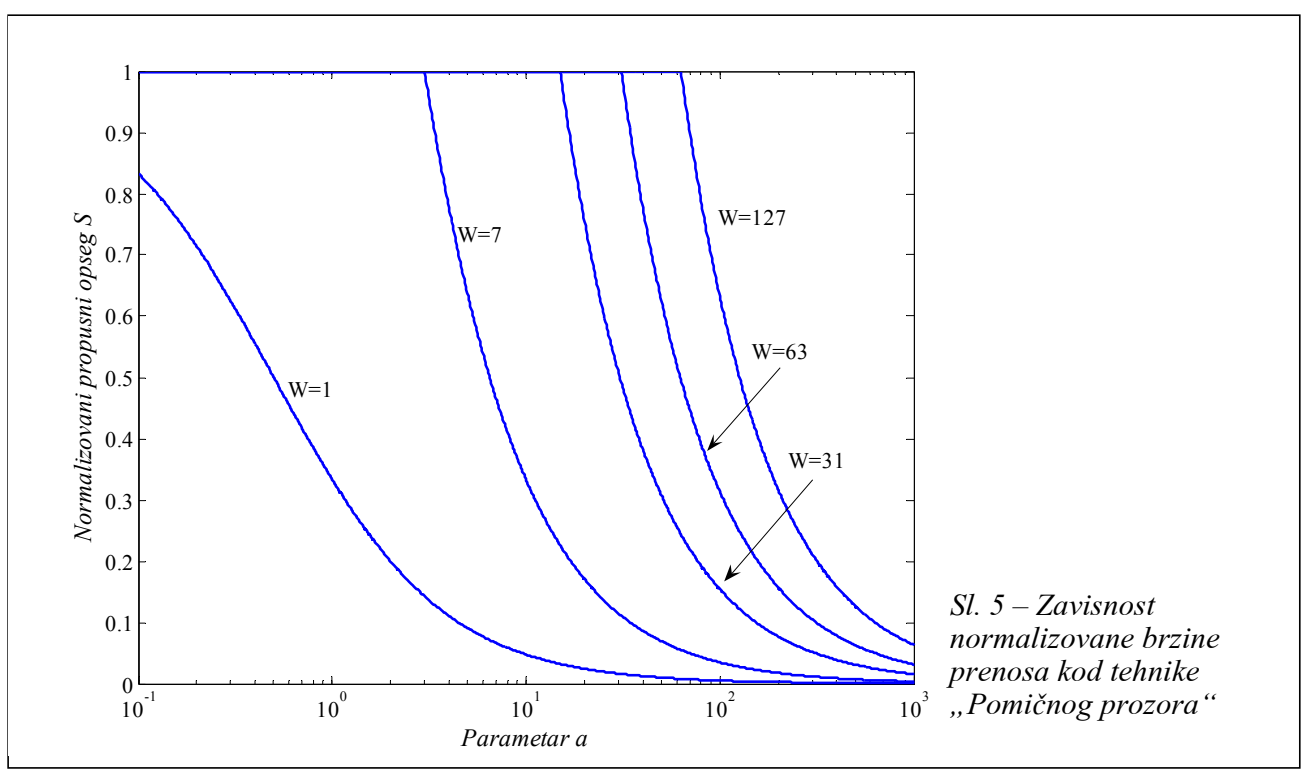


finisana, normalizovana propusna moć data je odnosom veličine prozora $W$ i periode trajanja $2 a+1$.

Imajući u vidu prethodno, dobija se:

$S=\left\{\begin{array}{cl}1, & W \geq 2 a+1 \\ \frac{W}{2 a+1}, & W<2 a+1\end{array}\right.$

Ako se broj sekvenci predstavi $n$ bitnim poljem, tada je maksimalna veličina prozora $W=2^{n}-1$. Na slici 5 predstavljena je maksimalna brzina prenosa koja se može postići za prozore veličine $W=1,7,31,63$ i 127 u funkciji parametra $a$. Prozor veličine $W=1$ odgovara algoritmu ,Stani i čekaj“. Vrednost od W=127 (7 bita) pokazuje bolje osobine za veće vrednosti $a$ i može se naći u WAN mrežama sa velikim brzinama prenosa.

\section{ARQ tehnika , Vrati unazad za $N^{\text {“ }}$ \\ (Go-back-N ARQ)}

Najčešći oblik kontrole greškama baziran na tehnici pomičnog prozora predstavlja „Vrati unazad za N“ (slika 6). Radi povećanja brzine prenosa podataka, kao i za održavanje konstantnog iznosa kašnjenja kod satelitskih kanala, ARQ postupak „Stani i čekaj“ zamenjen je strategijom kontinualnog prenosa.
U situacijama kada se pri prenosu ne dogodi greška, odredište će potvrditi dolazni ram sa signalom potvrde ,,Spreman na prijemu“ (RR - Receive Ready). Ukoliko odredište detektuje grešku u ra$\mathrm{mu}$, poslaće negativnu potvrdu, signal odbacivanja (REJ - Rejective). Stanica B će odbaciti taj ram i sve buduće dolazne ramove dok se ne primi ispravan ram. $\mathrm{Na}$ taj način izvorna stanica $A$, kada primi signal REJ, mora ponovo poslati ram koji je bio sa greškom, kao i sve ramove koji su poslati u meduvremenu.

Glavni nedostatak postupka ARQ sa povratkom unazad je u tome što kada se u nekoj kodnoj reči otkrije greška, prijemnik odbacuje narednih $\mathrm{N}-1$ primljenih reči, čak i u slučaju kada je većina njih ispravno primljena. Rezultat ovog postupka je da se za tih N-1 reči mora ponoviti predaja, što predstavlja gubitak vremena i kašnjenje, što u krajnjem slučaju dovodi do ozbiljne degradacije efikasnosti iskorišćenja kanala veze.

Da bi se ram uspešno preneo, srednji broj pokušaja $N_{x}$ odrediće se na osnovu matematičkog očekivanja:

$$
\begin{aligned}
N_{x}= & E[\text { ukupan_broj_prenetih_ } \\
& \text { ramova_bez_greške }] \\
N_{x}= & \sum_{i=1}^{\infty} f(i) P^{i-1}(1-P)
\end{aligned}
$$

Sl. 6-ARQ tehnika

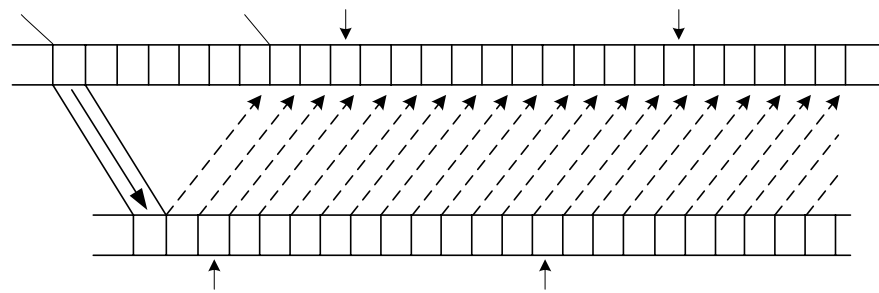


gde $f(i)$ predstavlja ukupan broj ramova koji će biti prenet ukoliko će se originalan ram preneti $i$ puta da bi prenos bio uspešan. Ako se sa $K$ označi broj ramova koji mora biti ponovo prenet zbog pojave greške u prenosu, vrednost $f(i)$ može se predstaviti na sledeći način:

$$
\begin{aligned}
& f(i)=1+(i-1) K \\
& f(i)=(1-K)+K i
\end{aligned}
$$

Imajući u vidu jednakosti

$\sum_{i=1}^{\infty} X^{i-1}=\frac{1}{1-X} \mathrm{i} \sum_{i=1}^{\infty}\left(i \cdot X^{i-1}\right)=\frac{1}{(1-X)^{2}}$ za $-1<\mathrm{X}<1$, može se napisati da je:

$$
\begin{aligned}
& N_{x}=(1-K) \sum_{i=1}^{\infty} P^{i-1}(1-P)+K \sum_{i=1}^{\infty} i P^{i-1}(1-P) \\
& N_{x}=1-K+\frac{K}{1-P}=\frac{1-P+K P}{1-P}
\end{aligned}
$$

Na slici 4 uočava se da je vrednost $K \cong 2 a+1$ za $W \geq(2 a+1)$ i $K=W$ za $W<(2 a+1)$. Ovako definisano $K$ daje:

$$
S=\left\{\begin{array}{cl}
\frac{1-P}{1+2 a P} ; & W \geq 2 a+1 \\
\frac{W(1-P)}{(2 a+1)(1-P+W P)} ; & W<2 a+1
\end{array}\right.
$$

Za $W=1$, oba algoritma, ,Selektivno odbacivanje“" i ,Vrati unazad za N“, potisnuti su algoritmom ,Stani i čekaj“. Na slici 7 prikazana je uporedna analiza ove tri tehnike kontrole i upravljanja greškama u prenosu kao funkcija parametra $a$ u slučaju verovatnoće $P=10^{-3}$. Međutim, ovaj grafik i prethodne jednačine ne uzimaju u obzir greške koje se mogu pojaviti u prenosu poruke potvrde (ACK), a takođe i kod tehnike „Vrati unazad za N“, zanemarene su greške koje se mogu pojaviti u retransmitovanim ramovima $u$ odnosu na originalan ram u kome se pojavila greška.

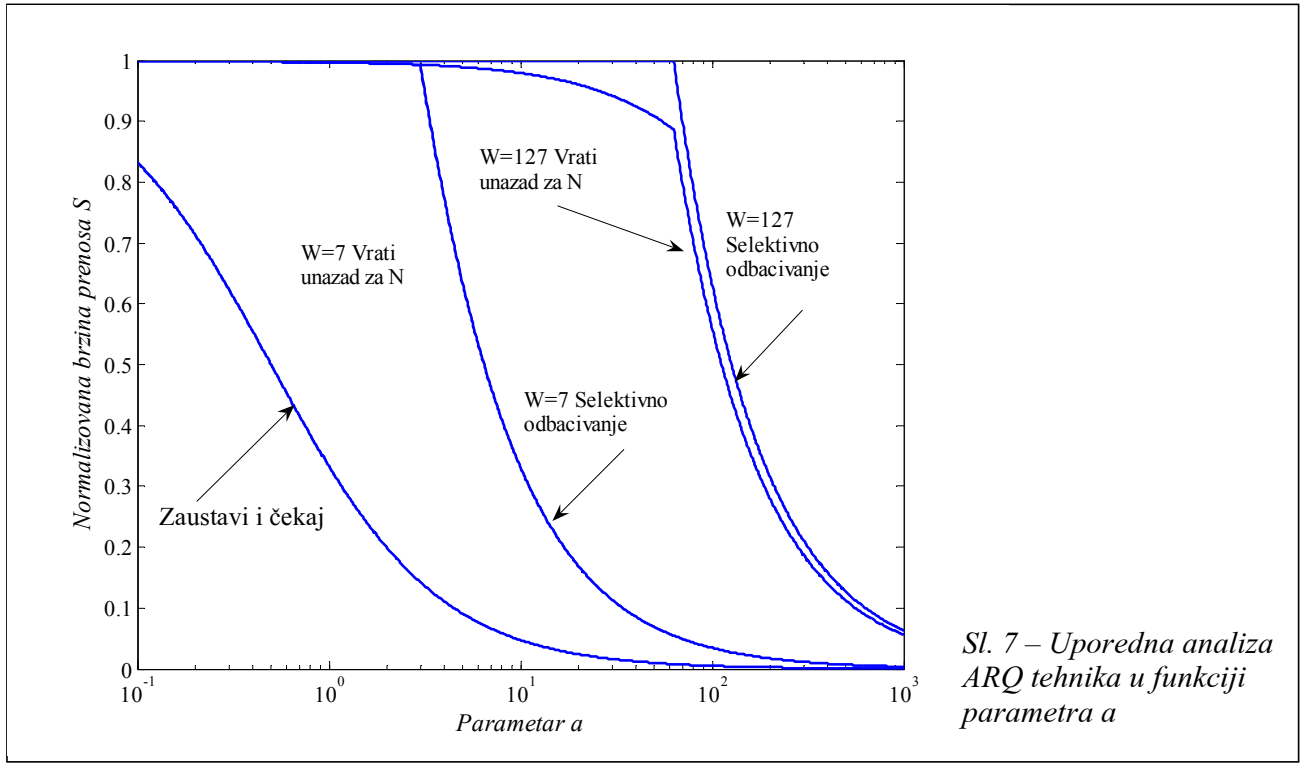


Na slici 7 može se uočiti da u slučaju veličine prozora $\mathrm{W}=7$ ( $\mathrm{n}=3$ bita), tehnike „Selektivno odbacivanje“ i „Vrati unazad za N" pokazuju praktično istu zavisnost vrednosti $\mathrm{S}$ od parametra $a$, dok je za vrednost $\mathrm{W}=127$ razlika evidentna. Na slici 8 pokazana je zavisnost normalizovane propusne moći $S$ za sve tri navedene ARQ tehnike u funkciji veličine prozora $\mathrm{W}$, gde se kao parametri pojavljuju vrednosti $a=10$ i $a=100$.

\section{ARQ tehnika ,, Selektivnog odbaci- vanja " (ARQ Selective-Reject)}

Sa ARQ tehnikom ,Selektivnog odbacivanja“" (slika 9) ramovi koji se ponovo šalju imaju negativnu poruku potvrde, NAK. Ova tehnika je efikasnija od prethodne, jer minimizira potrebno retransmitovanje ramova.

I ovde se kodne reči predaju u kontinuitetu. Međutim, ponavlja se otprema samo onih kodnih reči koje su negativno potvrđene (poruka NAK). Prijemni deo mora duže vreme komunicirati sa baferom, sve dok ne smesti sve NAK ramove i dok se ponovo ne prenese ram koji je bio sa greškom. Takođe, mora imati složenu logiku kojom se vrši ubacivanje pogrešnog rama u odgovarajuću sekvencu. S druge strane, predajnik, takođe, mora imati kompleksniju arhitekturu da bi mogao da šalje ram izvan sekvence. Zbog ovih zahteva ARQ tehnika „Selektivnog odbacivanja“" se, i pored svoje efikasnosti, ipak mnogo manje koristi od prethodne tehnike.

U slučaju pomičnog prozora, prethodna jednačina se primenjuje kada nema grešaka u prenosu. Kod ARQ sa selektivnim odbacivanjem potrebno je jednačinu (16) podeliti sa $N_{x}$, gde $N_{x}$ predstavlja srednji broj pokušaja da bi se okvir preneo bez greške: $N_{x}=\frac{1}{1-P}$, tako da se dobije sledeća vrednost propusne moći $S$ :

Sl. 8 - Zavisnost normalizovane brzine prenosa od širine prozora $W$

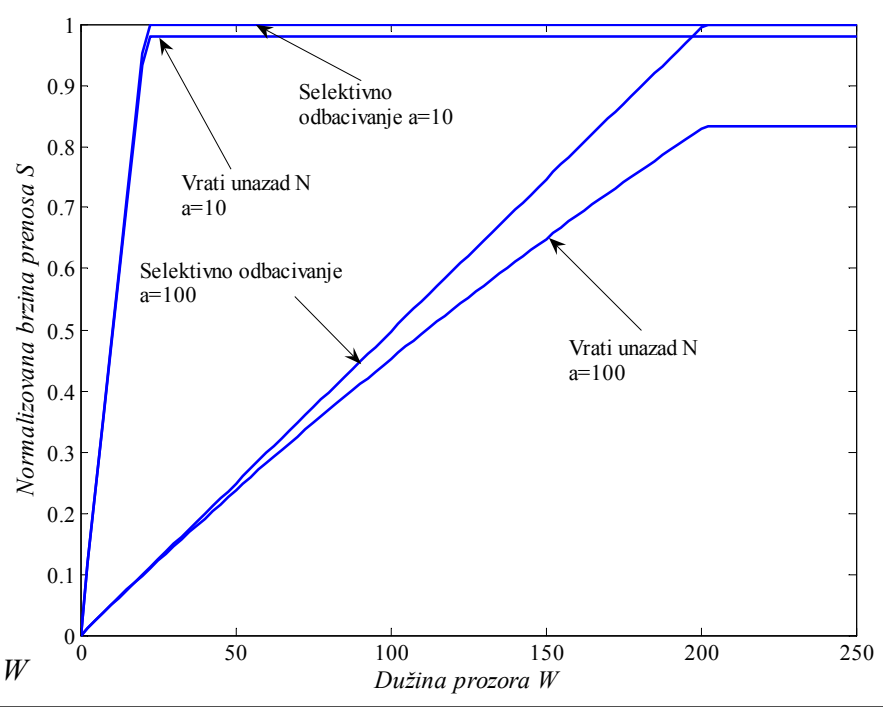




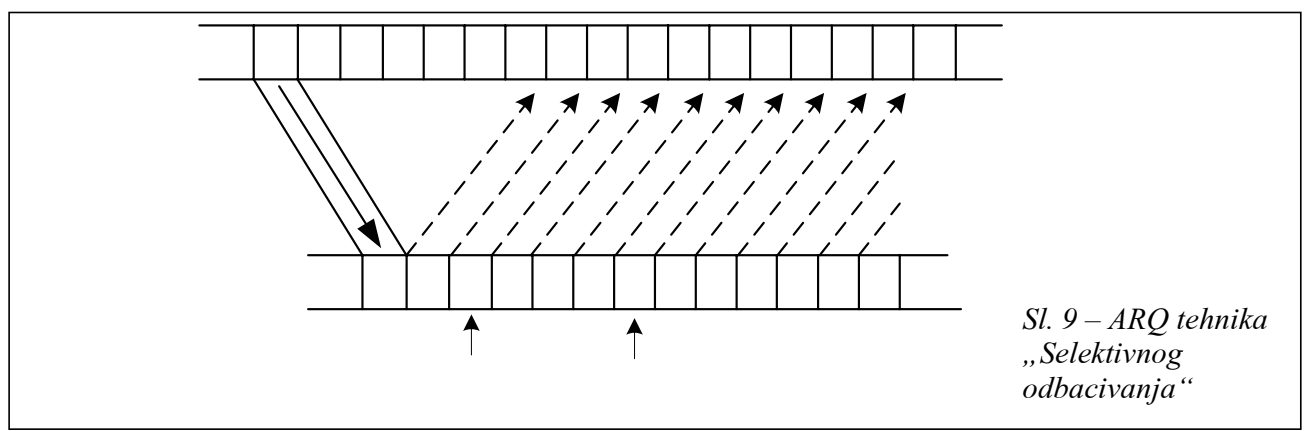

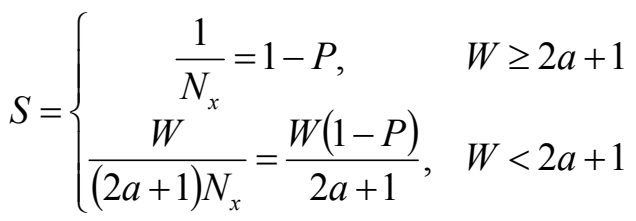

\section{Zaključak}

U ovom radu iznete su osnovne karakteristike procedura, odnosno tehnika upravljanja prenosom. Analizirana su dva slučaja: prvi, kada se pri prenosu ne pojavi greška i, drugi, sa greškom u prenosu. Detaljno je ukazano na osnovne relacije kojima se definišu karakteristična vremena u prenosu, parametar $S$ koji predstavlja normalizovanu brzinu prenosa na linku i parametar $a$ koji se definiše kao odnos ukupnog vremena prenosa na linku i vremena prenosa rama.

Analiziran je prenos u WAN mrežama ATM tehnikom. Za konkretne uslove prenosa dobijena je velika vrednost parametra $a$, što je rezultiralo malom efikasnošću linka, odnosno normalizovanom brzinom prenosa, a samim tim nemogućnošću primene ARQ tehnika. U slučaju LAN mreža, za konkretne vrednosti, dobijene su mnogo niže vrednosti za $a$, odnosno mnogo bolja vrednost normalizovane brzine prenosa $S$.
Prikazana je zavisnost normalizovane prenosne brzine $S$ od parametra $a$ za različite verovatnoće greške u prenosu $P$ kod tehnike „Stani i čekaj“. Pokazano je da za verovatnoće greške $P=10^{-3}$ i $P=10^{-2}$ praktično nema razlike, dok drastično smanjenje normalizovane vrednosti $S$ nastupa za grešku veću od 0,4 kada maksimalna vrednost $S$ za $a=0,1$ iznosi ispod 0,5 .

Prikazana je zavisnost $S$ od parametra $a$ kod ARQ tehnike „Pomičnog prozora", gde se kao parametar posmatra širina prozora $W$. Porast širine prozora $W$, uz porast par metrece conge to pljixh osobina po pitanjt normatidyate brzite prenosa u slučaju širokopojasnih WAN mreža. Prozor širine $W=1$ odgovara tehnici „Stani i čekaj“.

Izvršeno je upoređivanje zavisnosti normalizovane veličine $S$ u funkciji parametra $a$ u slučaju primene tehnika „Stani i čekaj“, „Vrati unazad za N“ i Sedacivanje“ za širinu prozora $W=127$. Tehnike upravljanja „Vrati unazad za N“ i „Selektivno odbacivanje“ ponašaju se identično za sve vrednosti parametra $a$, što je potvrdeno preklapanjem krivih zavisnosti. Za $W=127$, za vredno-

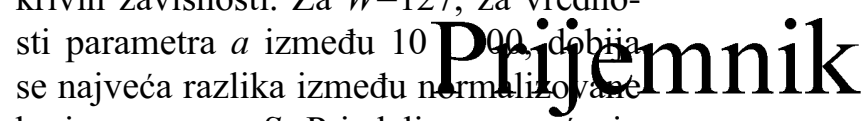
brzine prenosa $S$. Pri daljem povećanju parametra $a$, razlika u ponašanju $S$ izme- 
du ove dve tehnike ostaje konstantna, pri čemu tehnika „Selektivnog odbacivanja“ pokazuje bolje osobine $u$ odnosu na tehniku „Vrati unazad za N“.

Pokazana je i zavisnost normalizovane brzine prenosa $S$ od dužine prozora $W$ u slučaju tehnika „Selektivnog odbacivanja“ i „Vrati unazad za N“, gde se kao parametar posmatra $a$. Za vrednost $a=10 \mathrm{i}$ porast širine prozora do $W=20$, dobija se linearna zavisnost $S(W)$. Pri daljem povećanju $W$, kod obe tehnike, dobija se konstantna velika vrednost za $S$ koja je nešto niža kod tehnike „Vrati unazad za N“. Za $a=100$, linearna zavisnost $S$ od širine prozora $W$ ide do vrednosti $W=200$, pri čemu bolje karakteristike pokazuje tehnika „Selektivnog odbacivanja“. Pri daljem porastu širine prozora $W$ iznad 200, ,Selektiv- no odbacivanje" daje konstantnu vrednost za $S \approx 1$, dok tehnika „Vrati unazad za N“ daje lošiju vrednost, $S \approx 0,8$.

Pri analizi tehnika korišćen je programski jezik MATLAB 7.0 kojim su dobijeni svi analizirani grafički prikazi.

\section{Literatura:}

[1] Jevtović, M.: Projektovanje računarskih mreža, seminar, Elektrotehnički fakultet Banja Luka, jun 1997.

[2] Stallings, W.: High Speed Networks and Internets, Prentice-Hall, New Jersey, 2002.

[3] Lin, S.; Costello, D.; Miller, M.: Automatic-Repeat-Request Error-Control Schemes, IEEE CommunicationsMagazine, December 1984.

[4] Spragins, J.; Hammond, J.; Pawlikowski, K.: Telecommunications: Protocols and Design, Reading, MA: AddisonWesley, 1991.

[5] Warland, J.: Communication Networks: A First Course. New York: Mc Graw-Hill, 1998.

[6] Zorzi, M.; Rao, R.: On the Use of Renewal Theory in the Analysis of ARQ Protocols, IEEE Transactions on Communications, September, 1996. 